\title{
Invasive coronary angiography in patients with acute exacerbated COPD and elevated plasma troponin
}

\author{
Carmen Pizarro ${ }^{1, *}$ \\ Neele Herweg-Steffens ${ }^{1, *}$ \\ Martin Buchenroth ${ }^{2}$ \\ Wolfgang Schulte ${ }^{3}$ \\ Christian Schaefer ${ }^{\prime}$ \\ Christoph Hammerstingl' \\ Nikos Werner' \\ Georg Nickenig' \\ Dirk Skowasch' \\ 'Department of Internal Medicine \\ II - Cardiology, Pneumology and \\ Angiology, University Hospital Bonn, \\ Bonn, Germany; ${ }^{2}$ Department of \\ Pneumology, Johanniter Hospital \\ Bonn, Bonn, Germany; ${ }^{3}$ Department of \\ Pneumology, Malteser Hospital Bonn/ \\ Rhein-Sieg, Bonn, Germany \\ *These authors contributed equally \\ to this work
}

This article was published in the following Dove Press journal:

International Journal of COPD

16 September 2016

Number of times this article has been viewed

Background: In acute exacerbation of COPD, increased plasma levels of cardiac troponin are frequent and associated with increased mortality. Thus, we aimed at prospectively determining the diagnostic value of coronary angiography in patients with exacerbated COPD and concomitantly elevated cardiac troponin.

Patients and methods: A total of 88 patients (mean age $72.9 \pm 9.2$ years, $56.8 \%$ male) hospitalized for acute exacerbation of COPD with elevated plasma troponin were included. All patients underwent coronary angiography within 72 hours after hospitalization. Complementary 12-lead electrocardiogram, transthoracic echocardiography, pulmonary function, and angiological testing were performed.

Results: Coronary angiography objectified the presence of ischemic heart disease (IHD) in 59 patients $(67.0 \%)$, of whom 34 patients (38.6\% of total study population) underwent percutaneous coronary intervention. Among these 34 intervened patients, the vast majority $(n=26$, $76.5 \%$ ) had no previously known IHD, whereas only eight out of 34 patients $(23.5 \%)$ presented an IHD history. Patients requiring coronary intervention showed significantly reduced left ventricular ejection fraction $(45.8 \% \pm 13.1 \%$ vs $55.1 \% \pm 13.3 \%, P=0.01)$ and a significantly more frequent electrocardiographic ST-segment depression $(20.6 \%$ vs $7.4 \%, P=0.01)$. Neither additional laboratory parameters for inflammation and myocardial injury nor lung functional measurements differed significantly between the groups.

Conclusion: Angiographically confirmed IHD that required revascularization occurred in $38.6 \%$ of exacerbated COPD patients with elevated cardiac troponin. In this considerable portion of patients, coronary angiography emerged to be of diagnostic and therapeutic value.

Keywords: COPD, acute exacerbation, troponin elevation, coronary angiography, ischemic heart disease

\section{Introduction}

COPD constitutes a leading cause of disability and mortality worldwide, affecting $>10 \%$ of the adult population. ${ }^{1}$ As a complex respiratory disorder, its course is frequently complicated by its systemic manifestations. ${ }^{2}$ Among these, cardiovascular disease - in particular ischemic heart disease (IHD) - shows major affliction. ${ }^{3}$ Previous studies irrefutably indicate that recent respiratory infections are strongly associated with cardiovascular events, notably with myocardial infarction (MI). ${ }^{4}$ This contradicts the assumption that COPD and IHD are only linked to each other by their common risk profile, foremost smoking.

Exacerbations of COPD sustainably influence the natural history of the disease. Apart from accelerating the rate of lung function decline, ${ }^{5}$ periexacerbational
Correspondence: Carmen Pizarro Department of Internal Medicine II Cardiology, Pneumology and Angiology, University Hospital Bonn, Sigmund-FreudStraße 25, 53I05 Bonn, Germany

Tel $+49228287 \quad 15259$

Fax +49 $228287 \quad$ I 4323

Email carmen.pizarro@ukb.uni-bonn.de 
inflammation is not restricted to the airways but constitutes a systemic inflammatory process. ${ }^{6}$ In its course, an increase in inflammatory markers is detectable, predisposing to cardiovascular events such as MI. ${ }^{7}$ As such, elevation of cardiac troponin in the context of acute exacerbation of COPD (AECOPD) has frequently been observed. ${ }^{8,9}$ Though its increase has been associated with an increased risk of allcause mortality, ${ }^{10}$ its predictive value for IHD that requires revascularization remains undetermined.

Therefore, the aims of this prospective cohort study were 1) to determine the diagnostic yield of coronary angiography in patients hospitalized for AECOPD with concomitant troponinemia and 2) to correlate the angiographic results with the findings obtained by noninvasive cardiological testing.

\section{Methods}

Between July 2014 and December 2015, patient recruitment took place at three hospitals of Bonn (Germany): the University Hospital, the Johanniter Hospital, and the Malteser Hospital. Patients aged $\geq 18$ years with a history of spirometrically and clinically confirmed COPD and presenting with AECOPD at one of the hospitals' emergency departments were screened for eligibility for this prospectively conducted clinical cohort trial. In conformity with the Global Initiative for Chronic Obstructive Lung Disease (GOLD), ${ }^{1}$ acute exacerbation was defined by an acute, sustainable worsening of the patient's respiratory symptoms, leading to a change in medication. In all patients, cardiac troponin I (cTnI) was measured in the context of routine emergency department laboratory assessment. In case of an increase in cTnI, defined by a serum level exceeding $0.05 \mathrm{ng} / \mathrm{mL}$ (high-sensitivity troponin I assay; Siemens Healthcare GmbH, Erlangen, Germany), patients were confirmed eligible and asked for study participation. If patients initially presented at the Johanniter or Malteser Hospital's emergency units, they were transferred to the University Hospital's cardiological inpatient department to receive local medical care. Patients primarily recruited from the University Hospital's emergency department continued on-site medical treatment. Questionnaire-based recording of preexisting cardiac comorbidities and established risk factors for cardiovascular disorders was conducted. COPD staging was performed on the basis of pulmonary function testing results obtained in the last exacerbation-free period prior to hospitalization, as assessed by collection from the patient's medical reports. Exclusion criteria for study participation comprised principally ischemic pectoral symptomatology, severe renal insufficiency with an estimated glomerular filtration rate $<30 \mathrm{~mL} / \mathrm{min} / 1.73 \mathrm{~m}^{2}$, or acute kidney injury. Written informed consent was obtained from each patient at the time of confirmed troponin increase. The study was performed in accordance with the ethical guidelines of the 1975 Declaration of Helsinki and was approved by the Medical Ethics Committee of Bonn (Germany).

\section{Coronary angiography}

Within a timeframe of 72 hours after initial hospital presentation, all patients underwent coronary angiography (Allura Xper FD10/10; Philips Medical Systems, Koninklijke Philips N.V., Hamburg, Germany) with a transfemoral or transradial approach, as appropriate. In accordance with the European Society of Cardiology guidelines, ${ }^{11}$ IHD was defined as a degree of coronary stenosis $\geq 50 \%$. The concrete coronary interventional approach was left to the discretion of the treating operator and standard practice. ${ }^{11}$

\section{Electrocardiogram and transthoracic echocardiography}

At the time of initial diagnosis of cTnI elevation, 12-lead electrocardiogram was obtained, allowing for assessment of arrhythmias, complexes, and intervals, with special focus on signs of current ischemia or prior MI.

Transthoracic echocardiography was conducted at the University Hospital's cardiological unit prior to coronary angiography and was performed by experienced cardiac sonographers and cardiologists with multiannual technical expertise in echocardiographic circulatory imaging. Echocardiographic recordings were obtained by conventional equipment (Vivid 7; GE Healthcare Systems, Little Chalfont, United Kingdom; Philips Medical Systems, Koninklijke Philips N.V., Hamburg, Germany), in accordance with the recommendations of the American Society of Echocardiography. ${ }^{12}$

\section{Laboratory testing}

Immediately after patient's transfer to the University Hospital, a fasting blood sample was taken, encompassing full blood count, complete lipid panel, plasma glucose concentration, and high sensitivity C-reactive protein. Moreover, cardiac biomarkers of myocardial injury - creatine kinase, creatine kinase-myocardial band, and sequential cTnI were assessed. In case of patient's initial evaluation at the University Hospital, the aforementioned complementary blood sample was taken in an $\sim 4$-hour interval to the first cTnI measurement.

\section{Pulmonary function testing}

Subsequent to coronary angiography and in conformity with the European Respiratory Society guidelines, ${ }^{13}$ 
patients underwent postbronchodilator spirometry and body plethysmography. Parameters were recorded as absolute measures and percentages predicted for age, sex, and height indices. Concurrently, capillary blood gas analysis was performed for evaluation of oxygenation and ventilation status.

\section{Angiological testing}

With the objective of evaluating generalized atherosclerotic processes and arterial stiffness as an established independent predictor for cardiovascular risk, ${ }^{14}$ we measured brachialankle central pulse wave velocity (cPWV) using AngE Pro $8^{\circledR}$ (Sonotechnik Austria, Maria Rain, Austria), with values exceeding $12 \mathrm{~m} / \mathrm{s}$ considered to be pathological. Moreover, angiological diagnostics for peripheral arterial disease comprised assessment of the ankle-brachial index (ABI), obtained by division of the posterior tibial artery's systolic pressure by its brachial correlate. All angiological examinations were conducted in line with the current European guidelines. ${ }^{15}$

\section{Statistical analysis}

Descriptive data are presented as absolute numbers and percentages, mean \pm standard deviation - if normally distributed - or as median and range - if not normally distributed. In the case of continuous parameters, a Student's $t$-test or a Mann-Whitney $U$-test - as appropriate - was employed for comparison between two groups. For comparison of more than two groups, nonparametric testing by Kruskal-Wallis one-way analysis of variance was used. Categorical variables were analyzed for association using Pearson's $\chi^{2}$ test. Statistical significance was assumed when the null hypothesis could be rejected at $P<0.05$. All statistical analyses were performed using SPSS Statistics 23 software (IBM Corporation, Armonk, NY, USA).

\section{Results}

Demographic characteristics and clinical data of the 88 patients enrolled are summarized in Table 1. The study population exhibited a slight male predominance $(56.8 \%$, $\mathrm{n}=50)$ and a mean age of $72.9 \pm 9.2$ years. The vast majority of study participants had a smoking history $(60.2 \%$ and $37.5 \%$ were current and former smokers, respectively) and evidenced a median amount of $40.0(0-100)$ pack-years. As to stable course staging prior to exacerbation, $14.8 \%, 32.9 \%$, $21.6 \%$, and $30.7 \%$ of patients pertained to COPD GOLD groups A-D, respectively, with symptom severity evaluation performed using the COPD assessment test. At the time of hospitalization for exacerbation, pulmonary function testing revealed a mean forced expiratory volume in one second
Table I Demographic, clinical, and echocardiographic characteristics of total study population at the time of hospitalization for acute exacerbated COPD

\begin{tabular}{|c|c|}
\hline All patients, $n$ & 88 \\
\hline Age, years & $72.9 \pm 9.2$ \\
\hline Male sex, n (\%) & $50(56.8)$ \\
\hline \multicolumn{2}{|l|}{ COPD staging, $n(\%)^{a}$} \\
\hline GOLD A & $13(14.8)$ \\
\hline GOLD B & $29(32.9)$ \\
\hline GOLD C & $19(21.6)$ \\
\hline GOLD D & $27(30.7)$ \\
\hline \multicolumn{2}{|l|}{ Cardiovascular risk factors, $\mathrm{n}(\%)^{\mathrm{b}}$} \\
\hline Diabetes mellitus & $30(34.1)$ \\
\hline Arterial hypertension & $70(79.5)$ \\
\hline Hyperlipidemia & $34(38.6)$ \\
\hline Familial disposition & $19(21.6)$ \\
\hline Obesity & $32(36.4)$ \\
\hline \multicolumn{2}{|l|}{ Smoking status, n (\%) } \\
\hline Current smoker & $53(60.2)$ \\
\hline Former smoker & $33(37.5)$ \\
\hline Never smoker & $2(2.3)$ \\
\hline Pack-years & $40.0(0-100)$ \\
\hline \multicolumn{2}{|c|}{ Antiobstructive/antiinflammatory medication use at admission, $\mathrm{n}(\%)$} \\
\hline Long-term oxygen therapy & $3(3.4)$ \\
\hline Long-acting beta2 agonist & $65(73.9)$ \\
\hline Long-acting anticholinergic & $63(71.6)$ \\
\hline Inhaled glucocorticoids & $42(47.7)$ \\
\hline Systemic glucocorticoids & $13(14.8)$ \\
\hline PDE-4 inhibitor (roflumilast) & $6(6.8)$ \\
\hline \multicolumn{2}{|c|}{ Cardiovascular medication use at admission, $\mathrm{n}(\%)$} \\
\hline Platelet inhibitor & $19(21.6)$ \\
\hline Statin & $14(15.9)$ \\
\hline ACE inhibitor & $33(37.5)$ \\
\hline Angiotensin II receptor blocker & $16(18.2)$ \\
\hline Beta-blocker & $39(44.3)$ \\
\hline Calcium channel blocker & $20(22.7)$ \\
\hline Diuretics & $51(58.0)$ \\
\hline \multicolumn{2}{|l|}{ Echocardiographic parameters } \\
\hline LV ejection fraction, \% & $51.9 \pm 13.9$ \\
\hline \multicolumn{2}{|l|}{ Diastolic LV dysfunction, n (\%) } \\
\hline No diastolic LV dysfunction & $49(55.7)$ \\
\hline Grade I & $27(30.7)$ \\
\hline Grade II & $6(6.8)$ \\
\hline Grade III & $6(6.8)$ \\
\hline PASP, $\mathrm{mmHg}$ & $40.0 \pm 12.2$ \\
\hline \multicolumn{2}{|l|}{ PASP, n (\%) } \\
\hline$<30 \mathrm{mmHg}$ & $58(65.9)$ \\
\hline $30 \mathrm{mmHg}$ to $<50 \mathrm{mmHg}$ & $21(23.9)$ \\
\hline $50 \mathrm{mmHg}$ to $<70 \mathrm{mmHg}$ & $7(7.9)$ \\
\hline$\geq 70 \mathrm{mmHg}$ & $2(2.3)$ \\
\hline Wall motion abnormalities, $\mathrm{n}(\%)$ & $26(29.5)$ \\
\hline
\end{tabular}

Notes: Data are presented as total number and percentage (in parentheses), mean \pm $\mathrm{SD}$ or median and range (in parentheses). ${ }^{\mathrm{C}} \mathrm{COPD}$ staging is based on the pulmonary function testing results obtained in the last exacerbation-free period, as assessed by collection from the patient's medical reports. ${ }^{b} \mathrm{C}$ ardiovascular risk factors were recorded as self-reported by patients at hospital admission.

Abbreviations: GOLD, Global Initiative for Chronic Obstructive Lung Disease; PDE-4, phosphodiesterase-4; ACE, angiotensin-converting enzyme; LV, left ventricular; PASP, pulmonary arterial systolic pressure; SD, standard deviation. 
of $1.10 \mathrm{~L}( \pm 0.5 \mathrm{~L})$ in absolute terms or $44.2 \% \pm 16.9 \%$ of the predicted value. The residual volume averaged $4.06 \mathrm{~L}$ $( \pm 1.3 \mathrm{~L})$ or $172.6 \% \pm 63.4 \%$ of predicted value. In terms of capillary blood gas analysis, median resting oxygen tension accounted for $63.6 \mathrm{mmHg}(42.3-79.2 \mathrm{mmHg})$, with $4.5 \%$ of patients undercutting a value of $55 \mathrm{mmHg}$. Median carbon dioxide tension averaged $37.8 \mathrm{mmHg}(28.7-67.9 \mathrm{mmHg})$; hypercapnia was present in $4.5 \%$ of patients.

Coronary angiography identified IHD based on the presence of a coronary stenosis $\geq 50 \%$ in $67.0 \%(n=59)$ of the whole study population. Single-, two-, and three-vessel disease was present in $29.5 \%(n=26), 14.8 \%(n=13)$, and $22.7 \%$ $(n=20)$ of patients, respectively. A total of 34 participants, ie, $38.6 \%$ of the total study cohort, showed necessity for and underwent percutaneous coronary intervention. Distribution analysis of intervened coronary arteries identified the right coronary artery to be predominately affected (44.1\% of cases; Figure 1); left main coronary artery disease requiring revascularization was objectified in one patient who likewise received treatment by a percutaneous approach. Differentiation of the 34 intervened patients as a function of previously known IHD revealed $23.5 \%$ (8/34) of patients to have an IHD history, whereas in the vast majority of patients (26 out of 34 patients) no IHD was previously diagnosed. Neither the prevalence of IHD per se nor the presence of coronary lesions requiring revascularization significantly differed within COPD GOLD stages ( $P=0.66$ and $P=0.97$, respectively).

Laboratory data are given in Table 2. Mean cTnI level averaged $1.93 \pm 4.92 \mathrm{ng} / \mathrm{mL}$ and showed no significant distributive difference between patients with and without indication for percutaneous coronary intervention $(2.66 \pm 6.49 \mathrm{ng} / \mathrm{mL}$ vs $1.48 \pm 3.60 \mathrm{ng} / \mathrm{mL}$, respectively; $P=0.28$ ). Among those 34 patients undergoing coronary revascularization, 23 patients $(67.6 \%)$ had a rising sequential cTnI pattern by $150.7 \% \pm 50.6 \%$ of baseline value. Among those 54 patients without indication for percutaneous coronary intervention, a rising sequential cTnI pattern was exhibited by 38 patients $(70.4 \% ; 151.7 \% \pm 48.9 \%$ rise from baseline value) and did not significantly differ from that in intervened patients $(P=0.38)$. Likewise, the additionally assessed cardiac biomarkers of myocardial damage were balanced between groups. The sole laboratory parameters identified to correlate with the necessity for coronary revascularization were lowdensity lipoprotein cholesterol and fasting plasma glucose concentrations ( $P=0.04$ and $P<0.01$, respectively).

The 12-lead electrocardiographic and transthoracic echocardiographic results are outlined in Table 3 . The sole electrocardiographic finding that differed between groups was ischemic ST depression that was significantly more frequent among intervened patients $(P=0.01)$. A trend toward a major burden of tachycardiac heart rate alterations was ascertained in the intervened patient subgroup $(P=0.06)$. As to echocardiography, left ventricular ejection fraction was significantly lower in those patients undergoing coronary revascularization $(45.8 \% \pm 13.1 \%$ vs $55.1 \% \pm 13.3 \%, P=0.01)$.

In terms of angiological testing, mean calculated ABI values in patients requiring coronary intervention were $<0.9$ and thus implied lower extremity circulatory compromise.
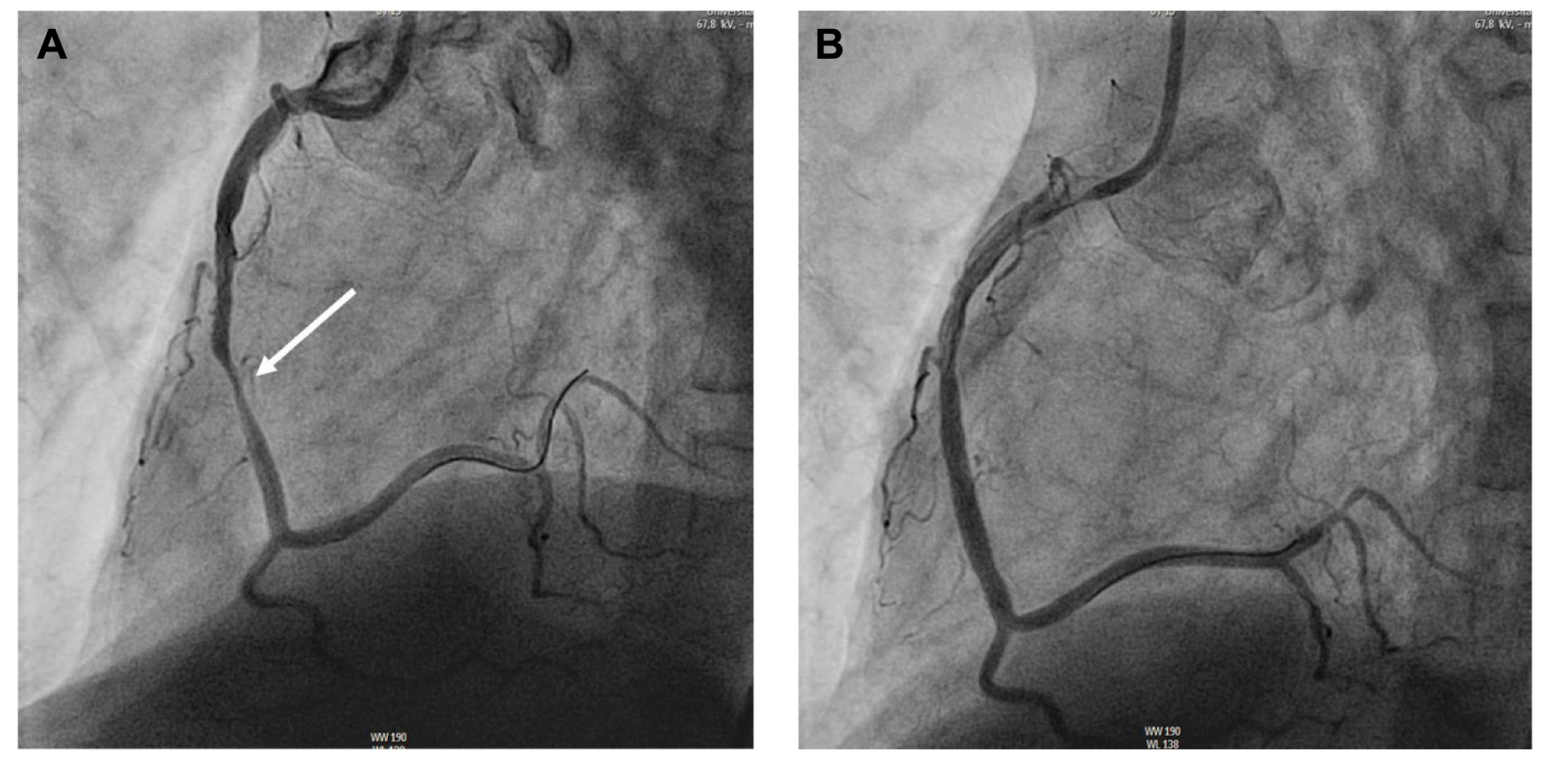

Figure I Coronary artery angiography of a 7I-year old male with acute exacerbated COPD GOLD D and elevated plasma troponin.

Notes: (A) Initial angiogram revealed single-vessel coronary artery disease with critical stenosis of mid-right coronary artery (90\%) (full-line arrow). The stenosis was treated by insertion of a drug-eluting stent (diameter: $3.5 \mathrm{~mm}$; length: $18.0 \mathrm{~mm}$ ). Part (B) illustrates the satisfactory final angiographic result immediately after stent implantation. 
Table 2 Comparison of laboratory and pulmonary parameters as a function of angiographically evidenced indication for percutaneous coronary intervention

\begin{tabular}{|c|c|c|c|}
\hline Categorical variables & $\begin{array}{l}\text { Patients with indication } \\
\text { for percutaneous coronary } \\
\text { intervention }(n=34)\end{array}$ & $\begin{array}{l}\text { Patients without indication } \\
\text { for percutaneous coronary } \\
\text { intervention }(n=54)\end{array}$ & $P$-value \\
\hline Age, years & $73.3 \pm 9.1$ & $72.8 \pm 9.4$ & 0.89 \\
\hline Male sex, n (\%) & $19(55.9)$ & $31(57.4)$ & 0.8 \\
\hline \multicolumn{4}{|l|}{ Laboratory parameters at admission } \\
\hline Cardiac troponin I, ng/mL & $2.66 \pm 6.49$ & $1.48 \pm 3.60$ & 0.28 \\
\hline CRP, mg/L & $57.4 \pm 76.6$ & $49.7 \pm 60.8$ & 0.62 \\
\hline D-Dimer, mg/L & $2.53 \pm 2.53$ & $1.72 \pm 1.44$ & 0.24 \\
\hline Leukocytes, $10^{9} / \mathrm{mL}$ & $11.9 \pm 3.8$ & $12.9 \pm 7.8$ & 0.48 \\
\hline Neutrophils, \% of leukocyte count & $82.0 \pm I I . I$ & $76.7 \pm 16.3$ & 0.14 \\
\hline Hemoglobin, g/dL & $13.0 \pm 2.1$ & $13.2 \pm 1.8$ & 0.58 \\
\hline Thrombocytes, $10^{9} / \mathrm{mL}$ & $258.7 \pm 99.9$ & $225.6 \pm 83.9$ & 0.09 \\
\hline Serum creatinine concentration, $\mathrm{mg} / \mathrm{dL}$ & $1.33 \pm 0.85$ & $1.33 \pm 0.58$ & I \\
\hline Glomerular filtration rate, $\mathrm{mL} / \mathrm{min}$ & $55.6 \pm 16.1$ & $53.2 \pm 16.7$ & 0.52 \\
\hline $\mathrm{CK}, \mathrm{U} / \mathrm{L}$ & $170.1 \pm 139.6$ & $247.4 \pm 325.9$ & 0.21 \\
\hline CK-MB, $\mu \mathrm{g} / \mathrm{L}$ & $11.3 \pm 18.8$ & $8.7 \pm 22.2$ & 0.49 \\
\hline Total cholesterol, mg/dL & $169.8 \pm 56.9$ & $161.9 \pm 33.3$ & 0.56 \\
\hline LDL cholesterol, mg/dL & $113.5 \pm 55.4$ & $93.4 \pm 32.0$ & 0.04 \\
\hline HDL cholesterol, mg/dL & $53.2 \pm 24.6$ & $53.9 \pm 23.1$ & 0.89 \\
\hline Triglycerides, mg/dL & $127.5 \pm 65.2$ & || $5.2 \pm 85 . \mid$ & 0.48 \\
\hline Glucose, mg/dL & $173.0 \pm 74.9$ & $136.7 \pm 49.7$ & $<0.01$ \\
\hline Pack-years & $53.9 \pm 24.4$ & $38.7 \pm 33.2$ & 0.16 \\
\hline \multicolumn{4}{|l|}{ Pulmonary function parameters ${ }^{a}$} \\
\hline $\mathrm{FEV}_{1}, \mathrm{~L}$ & $1.07 \pm 0.59$ & $1.11 \pm 0.49$ & 0.86 \\
\hline $\mathrm{FEV}_{1}, \%$ predicted & $41.8 \pm 16.9$ & $45.4 \pm 17.2$ & 0.61 \\
\hline$R V, L$ & $4.08 \pm 1.04$ & $4.05 \pm 1.41$ & 0.95 \\
\hline $\mathrm{RV}, \%$ predicted & $168.9 \pm 64.0$ & $174.4 \pm 65.5$ & 0.86 \\
\hline Forced vital capacity, L & $1.92 \pm 0.74$ & $1.73 \pm 0.72$ & 0.56 \\
\hline Forced vital capacity, \% predicted & $55.7 \pm 14.7$ & $52.4 \pm 14.5$ & 0.62 \\
\hline
\end{tabular}

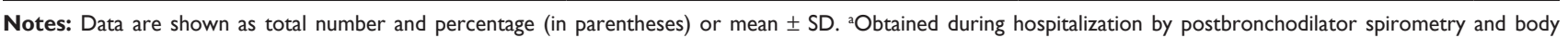
plethysmography. Statistical analyses were performed by use of Student's $t$-test or Mann-Whitney U-test, in the case of continuous parameters. Categorical variables were analyzed for association using Pearson's $\chi^{2}$ test. Statistical significance was assumed when the null hypothesis could be rejected at $P<0.05$.

Abbreviations: CRP, C-reactive protein; CK, creatine kinase; CK-MB, creatine kinase-myocardial band; LDL, low-density lipoprotein; HDL, high-density lipoprotein; $\mathrm{FEV}_{\text {1 }}$, forced expiratory volume in I second; RV, residual volume.

Pulse wave recording evidenced bilaterally concordant pulse wave indices. Neither pulse wave index nor cPWV differed between the groups (Table 3).

\section{Discussion}

In the present study, we aimed to determine the diagnostic value of invasive coronary angiography in patients with AECOPD and elevated cTnI levels. We observed that 1) coronary angiography detected IHD in 59 out of 88 examined patients $(67.0 \%)$. 2) IHD that required revascularization was present in $38.6 \%$ of total study population. 3 ) When compared with the results obtained by coronary angiography, the diagnostic value of noninvasive cardiological testing emerged to be moderate.

To the best of our knowledge, this is the first prospective study to invasively examine coronary status in AECOPD patients with troponinemia. In a considerable portion of patients, we identified cTnI elevation to occur as a consequence of MI that demanded coronary intervention.

Occurrence and frequency of acute exacerbation in COPD exert a sustainably negative impact on the disease's course not only by negatively affecting the patient's quality of life but also additionally and mainly by accelerating the rate of persistent lung function decline. ${ }^{5}$ As to exacerbation-related mortality, autopsy results attribute the leading cause of early death in hospitalized AECOPD patients to cardiac failure. ${ }^{16}$ The prevalence of increase in cardiac troponin during AECOPD has repeatedly been focused on and is reported to comprise percentages from $10 \%{ }^{17}$ up to $74 \%,{ }^{18}$ dependent on the employed assay's sensitivity. Against this backdrop, numerous efforts to identify its diagnostic value have been undertaken. In a recently published meta-analysis, a predictive role has been ascribed to derangements in cardiac troponin in hospitalized patients for AECOPD, as it was associated 
Table 3 Data comparison of noninvasive cardiological and angiological testing as a function of angiographically evidenced indication for percutaneous coronary intervention

\begin{tabular}{|c|c|c|c|}
\hline Categorical variables & $\begin{array}{l}\text { Patients with indication } \\
\text { for percutaneous coronary } \\
\text { intervention }(n=34)\end{array}$ & $\begin{array}{l}\text { Patients without indication } \\
\text { for percutaneous coronary } \\
\text { intervention }(n=54)\end{array}$ & $P$-value \\
\hline \multicolumn{4}{|l|}{ Cardiovascular risk factors, $\mathrm{n}(\%)^{\mathrm{a}}$} \\
\hline Diabetes mellitus & II (32.4) & $19(35.2)$ & 0.78 \\
\hline Arterial hypertension & $27(79.4)$ & $43(79.6)$ & 0.61 \\
\hline Hyperlipidemia & $15(44.1)$ & $19(35.2)$ & 0.21 \\
\hline Familial disposition & $7(20.6)$ & $12(22.2)$ & 0.51 \\
\hline Obesity & II (32.4) & $21(38.9)$ & 0.43 \\
\hline \multicolumn{4}{|l|}{ Echocardiographic parameters } \\
\hline LV ejection fraction, \% & $45.8 \pm 13.1$ & $55.1 \pm 13.3$ & 0.01 \\
\hline \multicolumn{4}{|l|}{ Diastolic LV dysfunction, n (\%) } \\
\hline No diastolic LV dysfunction & $16(47.0)$ & $33(6 I . I)$ & 0.41 \\
\hline Grade I & $12(35.3)$ & I 5 (27.8) & \\
\hline Grade II & $2(5.9)$ & $4(7.4)$ & \\
\hline Grade III & $4(I I .8)$ & $2(3.7)$ & \\
\hline PASP, $\mathrm{mmHg}$ & $39.5 \pm 9.7$ & $40.3 \pm 13.9$ & 0.85 \\
\hline Wall motion abnormalities, $\mathrm{n}(\%)$ & $9(26.5)$ & $17(3 \mid .5)$ & 0.80 \\
\hline \multicolumn{4}{|l|}{ Electrocardiographic changes, n (\%) } \\
\hline \multicolumn{4}{|l|}{ Rhythm } \\
\hline Sinus rhythm & $30(88.2)$ & $4 \mathrm{I}(75.9)$ & 0.21 \\
\hline Atrial fibrillation & $2(5.9)$ & $8(14.8)$ & \\
\hline Atrial flutter & $0(0)$ & I (I.9) & \\
\hline Paced rhythm & $2(5.9)$ & $4(7.4)$ & \\
\hline \multicolumn{4}{|l|}{ Heart rate } \\
\hline Bradycardia & I (2.9) & $2(3.7)$ & 0.06 \\
\hline Tachycardia & II (32.3) & II (20.4) & \\
\hline ST-segment depression & $7(20.6)$ & $4(7.4)$ & 0.01 \\
\hline$T$ wave inversion & $7(20.6)$ & I5 (27.8) & 0.62 \\
\hline \multicolumn{4}{|l|}{ Premature beats } \\
\hline Atrial & $5(14.7)$ & $5(9.3)$ & 0.42 \\
\hline Ventricular & I (2.9) & $2(3.7)$ & 0.79 \\
\hline \multicolumn{4}{|l|}{ Angiological testing } \\
\hline \multicolumn{4}{|l|}{$\mathrm{ABI}$} \\
\hline Right posterior tibial artery & $0.84 \pm 0.23$ & $1.08 \pm 0.39$ & 0.13 \\
\hline Left posterior tibial artery & $0.75 \pm 0.29$ & $1.19 \pm 0.31$ & $<0.01$ \\
\hline \multicolumn{4}{|l|}{ PWI } \\
\hline Right PWI & $577.5(\mid 28-1,000)$ & $290(134-1,000)$ & 0.64 \\
\hline Left PWI & $500.5(102-694)$ & $213(139-705)$ & 0.34 \\
\hline Central pulse wave velocity, $\mathrm{m} / \mathrm{s}$ & $8.2(2.5-18.2)$ & $6.7(4.6-10.3)$ & 0.52 \\
\hline
\end{tabular}

Notes: Data are presented as total number and percentage (in parentheses), mean \pm SD or median and range (in parentheses). ${ }^{a} \mathrm{Cardiovascular} \mathrm{risk} \mathrm{factors} \mathrm{were} \mathrm{recorded} \mathrm{as}$ self-reported by patients at hospital admission. Statistical analyses were performed by use of Student's $t$-test or Mann-Whitney $U$-test, in the case of continuous parameters. Categorical variables were analyzed for association using Pearson's $\chi^{2}$ test. Statistical significance was assumed when the null hypothesis could be rejected at $P<0.05$.

Abbreviations: LV, left ventricular; PASP, pulmonary arterial systolic pressure; ABI, ankle brachial index; PWI, pulse wave index; SD, standard deviation.

with an increased risk for all-cause mortality. ${ }^{10}$ Moreover, Campo et $\mathrm{al}^{19}$ reported positive troponin in AECOPD to be an independent predictor of cardiac death alone and of nonfatal MI; surprisingly, its prognostic role was limited to patients without previous IHD history. The term "cardiopulmonary continuum" summarizes this pathophysiological correlation between AECOPD and coronary processes.$^{20}$ As described by Gan et al, ${ }^{21}$ COPD is characterized by a systemic inflammatory process, whose dimension increases by acute exacerbatory events. Systemic inflammation markers comprising leukocytes, C-reactive protein, and diverse inflammatory cytokines have been identified to play a major role in COPD exacerbation frequency and severity, ${ }^{6}$ with low-grade systemic inflammation occurring in stable COPD. Likewise, inflammation promotes endothelial damage, resulting in endothelial dysfunction that in turn precedes atherosclerosis. An abrupt alteration in systemic inflammatory activity can cause silent atherosclerotic lesions to rupture with ensuing acute myocardial ischemia. ${ }^{22}$ In keeping with this and in order to estimate the systemic atherosclerotic effect induced by inflammation-enhanced endothelial dysfunction, we performed complementary angiological examination. 
In the setting of exacerbated and stable-state COPD, Patel et $\mathrm{al}^{23}$ reported arterial stiffness to rise acutely during exacerbation and to not recover for several weeks, with frequent COPD exacerbators manifesting a higher arterial stiffness than infrequent exacerbators. We presently assessed cPWV as a marker for arterial stiffness and ascertained no distributive differences between patients with and without indication for coronary revascularization; mean cPWV values were within the normal range in both cohorts. Nonetheless, intervened patients manifested a significant higher prevalence of concomitant peripheral artery disease, as defined by a reduction in ABI values, suggesting a systemic affection of inflammation-driven atherosclerotic lesions.

As a consequence of the aforementioned inflammationdriven proatherosclerotic processes, manifest atherosclerotic conditions, such as coronary artery disease, may develop. In this context, troponin elevation can be ascribed to spontaneous MI (type 1) consequent to atherosclerotic plaque rupture, ulceration, or dissection that induces myocyte necrosis. ${ }^{24}$ Alternative pathways responsible for troponin elevation during AECOPD comprehend: MI (type 2) due to an oxygen supply-demand imbalance, ${ }^{18}$ acute right ventricular dysfunction consequent to pressure elevation in the pulmonary circulation, and exacerbating left ventricular failure that secondarily causes AECOPD. Despite these diverse approaches, their respective causative values remain to be ascertained, in order to enable clinicians to decide to what extent patients with elevated cardiac troponin should receive a different treatment from those with normal values. ${ }^{25}$ In view of the abovementioned, we aimed at defining the role of type 1 and type 2 MI by prospectively performing coronary angiography. For this purpose, we consciously included all AECOPD patients irrespective of any prediagnosed IHD so as to prevent preselection and provide insights into the true risk for MI in this specific clinical setting. In line with the European Society of Cardiology guidelines, ${ }^{11}$ coronary angiography revealed concomitant IHD in $67.0 \%$ of patients. The portion of patients evidencing high-grade coronary stenosis and undergoing revascularization accounted for $38.6 \%$. Comparison to the data obtained by Stripe et $\mathrm{al}^{26}$ in a non-AECOPD cohort with mild troponin elevation ( $11 \%$ and $8.6 \%$ of patients had IHD and underwent revascularization, respectively) implies that troponinemia in AECOPD, when compared with troponinemia in a non-AECOPD setting, is a stronger indicator for coronary processes. Data comparison based upon the patient's history of IHD revealed no statistically significant intercohortal difference in the need for revascularization: $8 / 15$ patients $(53.3 \%)$ with and $26 / 73$ patients $(35.6 \%)$ without a prior history of IHD, respectively, received coronary intervention $(P=0.20)$. Moreover, though ST-segment depression and left ventricular systolic dysfunction were significantly more frequent in those patients requiring coronary revascularization, in 23 out of 34 intervened patients, both electro- and echocardiographic ischemic changes were absent. Among these 23 individuals, 15 patients had an increasing sequential cTnI pattern. The remaining eight out of 34 intervened patients had decreasing sequential cTnI values and normal electro- and echocardiographic findings. Thus, MI type 1, characterized by electroand echocardiographic ischemia and sequentially rising troponin values, was present in 26 patients $(76.5 \%$ of the intervened cohort), whereas troponin release in the remaining eight patients $(23.5 \%$ of the intervened cohort) was primarily attributable to an imbalance between myocardial oxygen supply and demand, designated as type $2 \mathrm{MI} .{ }^{27}$ There are several limitations of this study that should be addressed. The study design was cross-sectional and not drafted to perform longitudinal follow-up that in turn would have permitted estimation of the impact exerted by angiographic results on long-term mortality. Additional performance of coronary angiography in AECOPD patients without concomitant troponin elevation would have been a valuable comparatory complement to our observations, whose realization, however, emerges to be questionable from an ethical point of view. Though within guideline-defined standard clinical practice, the concrete choice of the interventional strategy was based on the operator's discretion and may therefore have affected our revascularization data. Finally and in view of the relative impreciseness of the official AECOPD definition, we cannot exclude with complete certainty that a portion of the patients studied may have had a primary coronary event that aggravated their dyspnea. Interestingly, among those patients who required percutaneous coronary intervention, the right coronary artery was preferentially affected and intervened ( $44.1 \%$ of cases). This raises the question if the resulting right ventricular dysfunction predisposes to be misinterpreted - in our study and in real-world settings - as a respiratory-driven event on the basis of a prediagnosed COPD.

\section{Conclusion}

Cardiac troponin elevation at the time of hospitalization for AECOPD is - in a considerable portion of patients indicative of IHD requiring revascularization. In the acute medical treatment of this portion of patients, invasive coronary angiography emerges to be of substantial diagnostic and therapeutic value. The establishment of a standardized diagnostic strategy to identify this portion of patients who require an invasive coronary approach is mandatory. 


\section{Acknowledgment}

The study was financially supported by Novartis Pharma GmbH (Nuremberg, Germany).

\section{Author contributions}

All authors contributed toward data analysis, drafting and critically revising the paper and agree to be accountable for all aspects of the work.

\section{Disclosure}

The authors report no conflicts of interest in this work.

\section{References}

1. Global Strategy for the Diagnosis, Management and Prevention of COPD, Global Initiative for Chronic Obstructive Lung Disease (GOLD) 2016 [homepage on the Internet]. Available from: http://www.goldcopd. org/. Accessed April 15, 2016.

2. Agusti A, Sobradillo P, Celli B. Addressing the complexity of COPD. Am J Respir Crit Care Med. 2011;183(9):1129-1137.

3. Mannino DM, Thorn D, Swensen A, Holguin F. Prevalence and outcomes of diabetes, hypertension and cardiovascular disease in COPD. Eur Respir J. 2008;32(4):962-969.

4. Clayton TC, Thompson M, Meade TW. Recent respiratory infection and risk of cardiovascular disease: case-control study through a general practice database. Eur Heart J. 2008;29(1):96-103.

5. Donaldson GC, Seemungal TA, Bhowmik A, Wedzicha JA. Relationship between exacerbation frequency and lung function decline in chronic obstructive pulmonary disease. Thorax. 2002;57(10):847-852.

6. Hurst JR, Perera WR, Wilkinson TM, Donaldson GC, Wedzicha JA. Systemic and upper and lower airway inflammation at exacerbation of chronic obstructive pulmonary disease. Am J Respir Crit Care Med.2006; 173(1):71-78.

7. Wedzicha JA, Seemungal TA, MacCallum PK, et al. Acute exacerbations of chronic obstructive pulmonary disease are accompanied by elevations of plasma fibrinogen and serum IL-6 levels. Thromb Haemost. 2000;84(2):210-215.

8. Brekke PH, Omland T, Holmedal SH, Smith P, Søyseth V. Troponin T elevation and long-term mortality after chronic obstructive pulmonary disease exacerbation. Eur Respir J. 2008;31(3):563-570.

9. Harvey MG, Hancox RJ. Elevation of cardiac troponins in exacerbation of chronic obstructive pulmonary disease. Emerg Med Australas. 2004;16(3):212-215.

10. Pavasini R, d'Ascenzo F, Campo G, et al. Cardiac troponin elevation predicts all-cause mortality in patients with acute exacerbation of chronic obstructive pulmonary disease: systematic review and metaanalysis. Int J Cardiol. 2015;191:187-193.

11. Roffi M, Patrono C, Collet JP, et al. 2015 ESC Guidelines for the management of acute coronary syndromes in patients presenting without persistent ST-segment elevation: task force for the management of acute coronary syndromes in patients presenting without persistent ST-segment elevation of the European Society of Cardiology (ESC). Eur Heart J. 2016;37:267-315.
12. Douglas PS, Garcia MJ, Haines DE, et al. ACCF/ASE/AHA/ASNC/ HFSA/HRS/SCAI/SCCM/SCCT/SCMR 2011 appropriate use criteria for echocardiography. J Am Soc Echocardiogr. 2011;24(3):229-267.

13. Miller MR, Hankinson J, Brusasco V, et al. Standardisation of spirometry. Eur Respir J. 2015;26(2):319-338.

14. Laurent S, Cockcroft J, Van Bortel L, et al; European Network for Noninvasive Investigation of Large Arteries. Expert consensus document on arterial stiffness: methodological issues and clinical applications. Eur Heart J. 2006;27(21):2588-2605.

15. Tendera M, Aboyans V, Bartelink ML, et al; ESC Committee for Practice Guidelines. ESC guidelines on the diagnosis and treatment of peripheral artery diseases: document covering atherosclerotic disease of extracranial carotid and vertebral, mesenteric, renal, upper and lower extremity arteries: the task force on the diagnosis and treatment of peripheral artery diseases of the European Society of Cardiology (ESC). Eur Heart J. 2011;32(22):2851-2906.

16. Zvezdin B, Milutinov S, Kojicic M, et al. A postmortem analysis of major causes of early death in patients hospitalized with COPD exacerbation. Chest. 2009;136(2):376-380.

17. McAllister DA, Maclay JD, Mills NL, et al. Diagnosis of myocardial infarction following hospitalisation for exacerbation of COPD. Eur Respir J. 2012;39(5):1097-1103.

18. Høiseth AD, Neukamm A, Karlsson BD, Omland T, Brekke PH, Søyseth V. Elevated high-sensitivity cardiac troponin $\mathrm{T}$ is associated with increased mortality after acute exacerbation of chronic obstructive pulmonary disease. Thorax. 2011;66(9):775-781.

19. Campo G, Pavasini R, Malagù $M$, et al. Relationship between troponin elevation, cardiovascular history and adverse events in patients with acute exacerbation of COPD. COPD. 2015;12(5):560-567.

20. Ukena C, Mahfoud F, Kindermann M, et al. The cardiopulmonary continuum systemic inflammation as 'common soil' of heart and lung disease. Int J Cardiol. 2010;145(2):172-176.

21. Gan WQ, Man SF, Senthilselvan A, Sin DD. Association between chronic obstructive pulmonary disease and systemic inflammation: a systematic review and a meta-analysis. Thorax. 2004;59(7):574-580.

22. Hansson GK. Inflammation, atherosclerosis, and coronary artery disease. N Engl J Med. 2005;352(16):1685-1695.

23. Patel AR, Kowlessar BS, Donaldson GC, et al. Cardiovascular risk, myocardial injury, and exacerbations of chronic obstructive pulmonary disease. Am J Respir Crit Care Med. 2013;188(9):1091-1099.

24. Brekke PH, Omland T, Smith P, Søyseth V. Underdiagnosis of myocardial infarction in COPD - Cardiac Infarction Injury Score (CIIS) in patients hospitalised for COPD exacerbation. Respir Med. 2008; 102(9):1243-1247.

25. Chang CL, Robinson SC, Mills GD, et al. Biochemical markers of cardiac dysfunction predict mortality in acute exacerbations of COPD. Thorax. 2011;66(9):764-768.

26. Stripe B, Rechenmacher S, Jurewitz D, Lee C, Schaefer S. The diagnostic yield of cardiac catheterization in low-risk troponinemia. JAMA Intern Med. 2013;173(22):2088-2090.

27. Thygesen K, Alpert JS, Jaffe AS, et al; Joint ESC/ACCF/AHA/WHF Task Force for the Universal Definition of Myocardial Infarction. Third universal definition of myocardial infarction. Circulation. 2012; 126(16):2020-2035. 
International Journal of COPD

\section{Publish your work in this journal}

The International Journal of COPD is an international, peer-reviewed journal of therapeutics and pharmacology focusing on concise rapid reporting of clinical studies and reviews in COPD. Special focus is given to the pathophysiological processes underlying the disease, intervention programs, patient focused education, and self management protocols.

This journal is indexed on PubMed Central, MedLine and CAS. The manuscript management system is completely online and includes a very quick and fair peer-review system, which is all easy to use. Visit http://www.dovepress.com/testimonials.php to read real quotes from published authors 